\title{
ĐÁNH GIÁ YẾU TỐ NGUY CƠ THEO THANG ĐIỂM CHA2DS2-VASc TRÊN BỆNH NHÂN ĐộT QUỴ CÓ RUNG NHĨ KHÔNG DO BỆHH VAN TIM Lê Gia Hoàng ${ }^{1}$, Hồ Anh Bình ${ }^{2}$ \\ 1. BV ĐK tỉnh Khánh Hoà, 2. BVTW Huế
}

DOI: $10.47122 / v j d e .2020 .44 .10$

\section{TÓM TẮT}

Đặt vấn đề: Chiến lược dự phòng huyết khối ở BN rung nhĩ không do bệnh van tim, dựa trên hệ thống phân tầng nguy cơ đột quy bằng thang điểm $\mathrm{CHA}_{2} \mathrm{DS}_{2}$-VASc và thuốc được chỉ định có thêm các kháng đông đường uống. Mục tiêu: Đánh giá yếu tố nguy cơ theo thang điểm cha ${ }_{2} \mathrm{ds}_{2}$-vasc trên bệnh nhân đột quỵ có rung nhĩ không do bệnh van tim. Phương pháp và đối tự̛ng nghiên cưu: Tiến hành nghiên cứu mô tả cắt ngang trên 91 bệnh nhân được chẩn đoán đột quỵ có rung nhĩ không do bệnh lý van tim. Kết quả: Điểm $\mathrm{CHA}_{2} \mathrm{DS}_{2}$-VASC trung bình là $4,80 \pm$ 1,56 điểm, nhóm $\leq 2$ điểm chiếm $9,9 \%$ và nhóm $>2$ điểm là $90,1 \%$. Nguy cơ đột quy não có $\mathrm{CHA}_{2} \mathrm{DS}_{2}$-VASc $=4-5$ chiếm $50,5 \%$; nguy cơ cao $\mathrm{CHA}_{2} \mathrm{DS}_{2}$-VASc $\geq 6$ là $30,8 \%$ và nguy cơ thấp là $18,7 \%$. Nữ có điểm $\mathrm{CHA}_{2} \mathrm{DS}_{2}$-VASc trung bình cao hơn nam $(p<0,01)$. Nhóm $\geq 75$ tuổi có điểm $\mathrm{CHA}_{2} \mathrm{DS}_{2}$-VASc trung bình cao hơn nhóm $<$ 75 tuổi $(\mathrm{p}<0,01)$. Nhóm THA, Suy tim, bệnh mạch máu có điểm $\mathrm{CHA}_{2} \mathrm{DS}_{2}$-VASc trung bình cao hơn nhóm không THA $(\mathrm{p}<0,05)$. Nhóm đái tháo đường có điểm $\mathrm{CHA}_{2} \mathrm{DS}_{2}$ VASc trung bình cao hơn nhóm không đái tháo đường $(\mathrm{p}>0,05)$. Nhóm tiền sử đột quy có điểm $\mathrm{CHA}_{2} \mathrm{DS}_{2}$-VASc trung bình cao hơn nhóm không có tiền sử đột quỵ $(\mathrm{p}<0,01)$. Kết luận: Hệ thống tính điểm $\mathrm{CHA}_{2} \mathrm{DS}_{2}$-VASc dễ thực hiện và khuyến cáo trong thực hành lâm sàng hàng ngày.

Tù khóa: Hệ thống tính điểm $\mathrm{CHA}_{2} \mathrm{DS}_{2}$ $V A S c$, đột quy, rung nhĩ không do bệnh van tim

\footnotetext{
ABSTRACT

To evaluate of risk factors by cha $_{2} d_{s_{2}}$-vasc score in Patients are diagnosed stroke with non-valvular atrial fibrillation
}

\section{Le Gia Hoang ${ }^{1}$, Ho Anh Binh ${ }^{2}$ \\ 1. Khanh Hoa General Hospital \\ 2. Hue Central Hospital}

Background: Thrombosis prevention strategy in non-valvular atrial fibrillation, according to stroke stratification by CHA2DS2-VASc score and adding oral anticoagulation drug to treatment. Objectives: To evaluate of risk factors by $\mathrm{cha}_{2} \mathrm{ds}_{2}$-vasc score in Patients are diagnosed stroke with non-valvular atrial fibrillation. Method: Descriptive cross-sectional study on 91 patients are diagnosed stroke with nonvalvular atrial fibrillation. Results: Average CHA2DS2-VASc score $4.80 \pm 1.56$ points, group $\leq 2$ points accounts for $9.9 \%$, group $>$ 2 points accounts for $90.1 \%$; - Risk of stroke with CHA2DS2-VASc score 4-5 points accounts for $50.5 \%$; high risk CHA2DS2VASc score $\geq 6$ accounts for $30.8 \%$ and low risk CHA2DS2-VASc score accounts for $18.7 \%$; - Average CHA2DS2-VASc score in female is higher than male $(\mathrm{p}<0.01)$; Average CHA2DS2-VASc score in group $\geq$ 75 years old is higher than in group $<75$ years old; - Average CHA2DS2-VASc score in group with hypertension, heart failure, vascular diseases is higher than in group without hypertension $(\mathrm{p}<0.05)$; - Average CHA2DS2-VASc score in group with diabetes is higher than in group without diabetes $(p>0.05)$; - Average CHA2DS2VASc score in group with pre-stroke is higher than in group without pre-stroke $(\mathrm{p}<0.01)$. Conclusion: CHA2DS2-VASc score is easily applicable and is recommended in routinely clinical practice.

Key words: CHA2DS2-VASc score, stroke, non-valvular atrial fibrillation

Ngày nhận bài: 29/10/2020

Ngày phản biện khoa học: 04/12/2020 
Ngày duyệt bài: 29/01/2021

Email: drhoanhbinh@gmail.com

Điện thoại: 0913489896

\section{1. ĐẶT VẤN ĐỀ}

Đối với rung nhĩ không do bệnh van tim, chiến lược dự phòng huyết khối dựa trên hệ thống phân tầng nguy cơ đột quỵ bằng thang điểm $\mathrm{CHA}_{2} \mathrm{DS}_{2}$-VASc và thuốc được chỉ định có thêm các kháng đông đường uống [29] Phân tầng nguy cơ đột quỵ là hết sức quan trọng trong việc phân loại mức độ nguy cơ cho mỗi bệnh nhân đột quỵ có rung nhĩ và hướng xử trí bệnh. Việc phân tầng nguy cơ đột quỵ trước đây dựa vào hệ thống tính điểm $\mathrm{CHADS}_{2}$. Tuy nhiên sau một thời gian ứng dụng người ta đã thấy có một số hạn chế như: bỏ qua một số yếu tố nguy cơ và không hướng dẫn chi tiết về việc chọn lựa thuốc chống huyết khối đối với điểm $\mathrm{CHADS}_{2}$ $=1$. Do vậy, Hội tim mạch Châu Âu đã cho ra đời thang điểm mới có nhiều điểm sửa đổi và dễ dàng ứng dụng, đó là hệ thống tính điểm $\mathrm{CHA}_{2} \mathrm{DS}_{2}$-VASc và đã được khuyến cáo trong thực hành lâm sàng hàng ngày [21]. Mục tiêu: Đánh giá yếu tố nguy cơ theo thang điểm cha $a_{2} s_{2}$-vasc trên bệnh nhân đột quy có rung nhĩ không do bệnh van tim.

\section{2. ĐỐI TƯợNG VÀ PHƯƠNG PHÁP NGHIÊN CÚU}

\section{1. Đối tượng nghiên cứu}

\subsubsection{Tiêu chuẩn chọn bệnh nhân nghiên cứu}

Bệnh nhân phải được chẩn đoán đột quỵ có rung nhĩ không do bệnh lý van tim[6],[7]

+ Tiêu chuẩn chẩn đoán rung nhĩ: [6]

+ Tiêu chuẩn chẩn đoán đột quy thiếu máu cuc bộ: [7]

\subsubsection{Tiêu chuẩn lọ̣i trù̀ bệnh nhân} nghiên cúu

- Bệnh nhân không đồng ý tham gia nghiên cứu.

- Bệnh nhân đột quỵ chảy máu não.

- Bệnh nhân đột quỵ nhồi máu não do u hoặc chấn thương.

- Bệnh nhân có bệnh lý van tim có/không rung nhĩ

2.1.3. Thời gian và địa điểm nghiên cúu

Bệnh nhân đột quỵ có rung nhĩ nhập viện vào khoa nội tim mạch của bệnh viện đa khoa tỉnh Khánh Hoà

Thời gian từ tháng 4.2019 đến tháng 4 . 2020.

\subsection{Phương pháp nghiên cứu}

2.2.1. Thiết kế nghiên cúu

Phương pháp nghiên cứu cắt ngang mô tả

\subsubsection{Các bước tiến hành}

- Thu nhập phần hành chính:

- Khai thác về tiền sử và bệnh sử:

- Thang điểm đánh giá nguy cơ đột quỵ do huyết khối ở các bệnh nhân rung nhĩ không do bệnh van tim CHA2DS2-VASc [14]

\begin{tabular}{|c|c|c|}
\hline \multicolumn{2}{|c|}{ Yếu tố nguy cơ lâm sàng } & \multirow{2}{*}{$\begin{array}{c}\text { CHA2DS2-VASc } \\
1\end{array}$} \\
\hline Suy tim sung huyết & (으gestive Heart Failure) & \\
\hline Tăng huyết áp & (Hypertension) & 1 \\
\hline Tuổi trên 75 & $(\underline{\text { Age })}$ & 2 \\
\hline Đái tháo đường & (Diabetes Mellitus) & 1 \\
\hline Tiền sử đột quỵ & (Stroke) & 2 \\
\hline Bệnh mạch máu & (Vascular disease) & 1 \\
\hline \multicolumn{2}{|c|}{ Tổng } & 9 \\
\hline
\end{tabular}

- Không có nguy cơ ( $\mathrm{CHA}_{2} \mathrm{DS}_{2}$-VASC $\left.=0\right)$

- Nguy cơ trung bình $\left(\mathrm{CHA}_{2} \mathrm{DS}_{2}-\mathrm{VASC}=1-2\right)$

- Nguy cơ cao $\left(\mathrm{CHA}_{2} \mathrm{DS}_{2}\right.$-VASC $\left.>2\right)$

2.2.3. Phuơng pháp xử lý số liệu 

22.0.

Việc nhập và xử lý số liệu được thực hiện trên máy vi tính theo chương trình Excel 2010, SPSS

\section{KẾT QUẢ NGHIÊN CÚU}

Quan nghiên cứu điều tra 91 đối tượng về yếu tố nguy cơ trên bệnh nhân đột quỵ không có van tim, chúng tôi có kết quả như sau:

3.1. Đặc điểm chung của đối tượng nghiên cứu

Bảng 3.1. Tỷ lệ đối tượng nghiên cứu theo tuổi

\begin{tabular}{|l|c|c|}
\hline \multicolumn{1}{|c|}{ Nhóm tuổi } & n & Tỷ lệ \% \\
\hline$<65$ tuổi & 10 & 11,0 \\
\hline $65-74$ tuổi & 25 & 27,5 \\
\hline$\geq 75$ tuổi & 56 & 61,5 \\
\hline Tổng cộng & $\mathbf{9 1}$ & $\mathbf{1 0 0 , 0}$ \\
\hline Tuổi TB $(\mathrm{X} \pm$ SD) & $73,36 \pm 8,92$ tuổi, $\mathrm{T}_{\min }=56, \mathrm{~T}_{\max }=95$ \\
\hline
\end{tabular}

Nhận xét: Nhóm đối tượng $\geq 75$ tuổi chiếm tỷ lệ cao nhất với $61,5 \%$; nhóm $<65$ tuổi là $11,0 \%$. Tuổi TB là 73,36 $\pm 8,92$ tuổi;

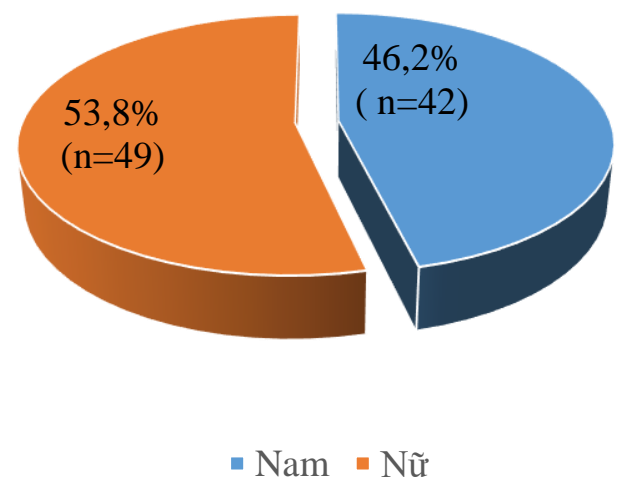

Biểu đồ 3.1. Tỷ lệ đối tượng nghiên cứu theo giới

Nhận xét: Nữ có tỷ lệ cao hơn nam (53,8\% so với 46,2\%).

Bảng 3.2. Triệu chứng lâm sàng của bệnh nhân nghiên cứu

\begin{tabular}{|l|c|c|}
\hline \multicolumn{1}{|c|}{ Triệu chứng lâm sàng } & n & Tỷ lệ \% \\
\hline Liệt nửa người & 65 & 71,4 \\
\hline Đau đầu & 11 & 12,1 \\
\hline Rối loạn ngôn ngữ & 22 & 24,2 \\
\hline Rối loạn tri giác & 20 & 22,0 \\
\hline Liệt mặt & 6 & 6,6 \\
\hline Co giật & 4 & 4,4 \\
\hline Chóng mặt & 1 & 1,4 \\
\hline
\end{tabular}

Nhận xét: $71,4 \%$ bệnh nhân liệt nửa người; $24,2 \%$ có rối loạn ngôn ngữ; $22,0 \%$ rối loạn trí giác và chỉ $1,4 \%$ chóng mặt. 




Biểu đồ 3.3. Tiền sử bệnh

Nhận xét: 91 bệnh nhân nghiên cứu có tiền sử bệnh mạch máu chiếm tỷ lệ cao nhất 89,0\%; tiếp đến là tăng huyết áp $(74,7 \%)$, suy tim $(45,1 \%)$,

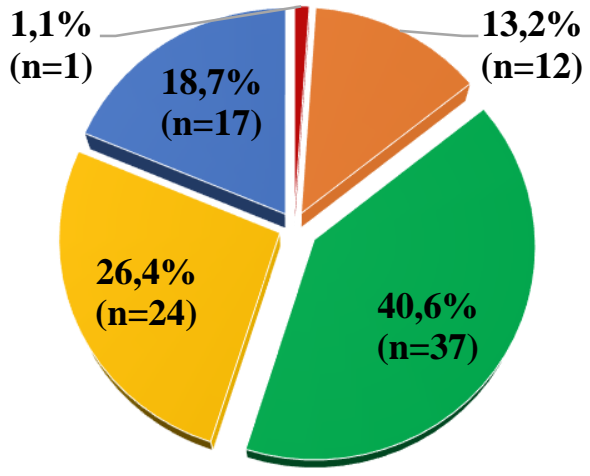

- Không có TS

bệnh

- TS có 1 bệnh

- TS có 2 bệnh

TS có 3 bệnh

- TS có 4 bệnh

Biểu đồ 3.4. Đặc điểm nhóm bệnh nhân có tiền sử bệnh phối hợp

Nhận xét: Bệnh nhân có tiền sử 2 bệnh phối hợp chiếm tỷ lệ cao nhất 40,6\%; tiếp đến có TS 3 bệnh phối hợp là $26,4 \%$; tiền sử có 4 bệnh là $18,7 \%$;

3.2. Yếu tố nguy cơ theo thang điểm $\mathrm{CHA}_{2} \mathrm{DS}_{2}$-VASC

Bảng 3.3. Tỷ lẹ điểm $C H A_{2} D S_{2}-V A S c$ của bệnh nhân

\begin{tabular}{|c|c|c|}
\hline Điểm & Số bệnh nhân & Tỷ lệ \\
\hline 2 & 9 & 9,9 \\
\hline 3 & 8 & 8,8 \\
\hline 4 & 21 & 23,1 \\
\hline 5 & 25 & $\mathbf{2 7 , 5}$ \\
\hline 6 & 13 & 14,3 \\
\hline 7 & 12 & 13,2 \\
\hline 8 & 3 & 3,3 \\
\hline Tồng & $\mathbf{9 1}$ & $\mathbf{1 0 0 , 0}$ \\
\hline CHA2 $_{2}$ DS 2 -VASc TB (X \pm SD) & \multicolumn{2}{|c|}{$4,80 \pm 1,56$} \\
\hline Min - Max & \multicolumn{2}{|c|}{$2-8$} \\
\hline
\end{tabular}


Nhận xét: Điểm TB của $\mathrm{CHA}_{2} \mathrm{DS}_{2}$-VASC là $4,80 \pm 1,56$ điểm. Nhóm $\leq 2$ điểm chiếm $9,9 \%$ và nhóm $>2$ điểm là $90,1 \%$

Bảng 3.4. Mức độ nguy cơ đột quy

\begin{tabular}{|l|c|c|}
\hline \multicolumn{1}{|c|}{ Mức độ nguy co } & n & Tỷ lệ (\%) \\
\hline Nguy cơ thấp $\left(\mathrm{CHA}_{2} \mathrm{DS}_{2}-\mathrm{VASC}_{2}=0-1\right)$ & 0 & 0,0 \\
\hline Nguy cơ trung bình $\left(\mathrm{CHA}_{2} \mathrm{DS}_{2}\right.$-VASC $\left.=2-3\right)$ & 17 & 18,7 \\
\hline Nguy cơ cao $\left(\mathrm{CHA}_{2} \mathrm{DS}_{2}\right.$-VASC $\left.\geq 4\right)$ & 74 & 81,3 \\
\hline Tổng & $\mathbf{9 1}$ & $\mathbf{1 0 0}$ \\
\hline
\end{tabular}

Nhận xét: Có 17 bệnh nhân nguy cơ trung bình chiếm $18,7 \%$ và nguy cơ cao là $81,3 \%$ không có nguy cơ thấp.

\begin{tabular}{|c|c|c|}
\hline & & \\
\hline 8 biến số & Số bệnh nhân & Tỷ lệ \\
\hline Suy tim & 41 & 45,1 \\
\hline Tăng huyết áp & 68 & 74,7 \\
\hline Tuổi $\geq 75$ & 56 & 61,5 \\
\hline Đái tháo đường & 11 & 12,1 \\
\hline Tiến sử đột quỵ & 25 & 27,5 \\
\hline Bệnh mạch máu & 81 & 89,0 \\
\hline Tuổi 65- 74 & 25 & 27,5 \\
\hline Giới nữ & 49 & 53,8 \\
\hline
\end{tabular}

Nhận xét: $89,0 \%$ bệnh nhân nghiên cứu có bệnh mạch máu, $74,7 \%$ tăng huyết áp, $61,5 \%$ là tuổi $\geq 75$ và $53,8 \%$ là nữ.

Bảng 3.6. Điểm $\mathrm{CHA}_{2} \mathrm{DS}_{2}-\mathrm{VASc}$ của $\mathrm{BN}$ nghiên cứu theo giới

\begin{tabular}{|c|c|c|c|}
\hline Giới & $\mathbf{n}$ & $\mathbf{X} \pm$ SD & p \\
\hline Nam & 42 & $4,26 \pm 1,42$ & \multirow{2}{*}{$<0,01$} \\
\hline Nữ & 49 & $5,27 \pm 1,54$ & \\
\hline Chung & 91 & $4,80 \pm 1,56$ & \\
\hline
\end{tabular}

Nhận xét: Nữ có $\mathrm{CHA}_{2} \mathrm{DS}_{2}$-VASc trung bình cao hơn nam 5,27 $\pm 1,54$ điểm so với 4,26 $\pm 1,42$ điểm, sự khác biệt có ý nghĩa thống kê $(\mathrm{p}<0,01)$.

Bảng 3.7. Điểm $\mathrm{CHA}_{2} D S_{2}-V A S c$ của BN nghiên cứu theo tuổi

\begin{tabular}{|c|c|c|c|}
\hline Tuổi & $\mathbf{n}$ & $\mathbf{X} \pm$ SD & \multirow{2}{*}{$<0,01$} \\
\hline$<75$ & 35 & $3,94 \pm 1,64$ & \\
\hline$\geq 75$ & 56 & $5,34 \pm 1,24$ & \\
\hline Chung & 91 & $4,80 \pm 1,56$ & \\
\hline
\end{tabular}

Nhận xét: Nhóm $\geq 75$ tuổi có $\mathrm{CHA}_{2} \mathrm{DS}_{2}$-VASc trung bình cao hơn nhóm $<75$ tuổi 5,34 $\pm 1,24$ điểm so với 3,94 $\pm 1,64$ điểm, $(\mathrm{p}<0,01)$.

Bảng 3.8. Điểm $\mathrm{CHA}_{2} \mathrm{DS} \mathrm{S}_{2}$-VASc của BN nghiên cứu theo $H A$

\begin{tabular}{|c|c|c|c|}
\hline Huyết áp & $\mathbf{n}$ & $\mathbf{X} \pm \mathbf{S D}$ & $\mathbf{p}$ \\
\hline Có tăng huyết áp & 68 & $5,01 \pm 1,53$ & \multirow{2}{*}{$<0,05$} \\
\hline Không có bệnh tăng huyết áp & 23 & $4,17 \pm 1,50$ & \\
\hline Chung & $\mathbf{9 1}$ & $\mathbf{4 , 8 0 \pm 1 , 5 6}$ & \\
\hline
\end{tabular}

Nhận xét: Nhóm THA có $\mathrm{CHA}_{2} \mathrm{DS}_{2}$-VASc trung bình cao hơn nhóm không THA là 5,01 $\pm 1,53$ điểm so với $4,17 \pm 1,50$ điểm, $(\mathrm{p}<0,05)$ 
Bảng 3.9. Điểm $\mathrm{CHA}_{2} \mathrm{DS}_{2}$-VASc của $\mathrm{BN}$ nghiên cứu theo suy tim

\begin{tabular}{|c|c|c|c|}
\hline Suy tim & n & $\mathbf{X} \pm$ SD & p \\
\hline Có suy tim & 41 & $5,63 \pm 1,48$ & \multirow{2}{*}{$<0,01$} \\
\hline Không có suy tim & 50 & $4,12 \pm 1,27$ & \\
\hline Chung & $\mathbf{9 1}$ & $\mathbf{4 , 8 0} \pm \mathbf{1 , 5 6}$ & \\
\hline
\end{tabular}

Nhận xét: Nhóm suy tim có $\mathrm{CHA}_{2} \mathrm{DS}_{2}$-VASc trung bình cao hơn nhóm không suy tim là 5,63 $\pm 1,48$ điểm so với $4,12 \pm 1,27$ điểm, $(\mathrm{p}<0,05)$

Bảng 3.10. Điểm $C H A_{2} D S_{2}$-VASc của bệnh nhân theo đái tháo đường

\begin{tabular}{|c|c|c|c|}
\hline Đái tháo đường & $\mathbf{n}$ & $\mathbf{X} \pm \mathbf{S D}$ & $\mathbf{p}$ \\
\hline Có đái tháo đường & 11 & $5,64 \pm 1,50$ & \multirow{2}{*}{$>0,05$} \\
\hline Không có đái tháo đường & 80 & $4,69 \pm 1,54$ & \\
\hline Chung & $\mathbf{9 1}$ & $\mathbf{4 , 8 0} \pm \mathbf{1 , 5 6}$ & \\
\hline
\end{tabular}

Nhận xét: Nhóm đái tháo đường có $\mathrm{CHA}_{2} \mathrm{DS}_{2}$-VASc trung bình cao hơn nhóm không đái tháo đường là $5,64 \pm 1,50$ điểm so với 4,69 $\pm 1,54$ điểm $(\mathrm{p}>0,05)$

Bảng 3.11. Điểm $C H A_{2} D S_{2}$-VASc của bệnh nhân theo tiền sủ đột quy.

\begin{tabular}{|c|c|c|c|}
\hline Tiền sử đột quy. & $\mathbf{n}$ & $\mathbf{X} \pm$ SD & p \\
\hline Có TS đột quỵ & 25 & $6,16 \pm 1,34$ & \multirow{2}{*}{$<0,01$} \\
\hline Không có TS đột quỵ & 66 & $4,29 \pm 1,31$ & \\
\hline Chung & $\mathbf{9 1}$ & $\mathbf{4 , 8 0} \pm \mathbf{1 , 5 6}$ & \\
\hline
\end{tabular}

Nhận xét: Nhóm tiền sử đột quỵ có $\mathrm{CHA}_{2} \mathrm{DS}_{2}$-VASc trung bình cao hơn nhóm không có tiền sử đột quỵ là $6,16 \pm 1,34$ điểm so với $4,29 \pm 1,31$ điểm, $(\mathrm{p}<0,01)$

Bảng 3.12. Điểm $\mathrm{CHA}_{2} D S_{2}-V A S c$ của bệnh nhân theo bệnh mạch máu

\begin{tabular}{|c|c|c|c|}
\hline Bệnh mạch máu & $\mathbf{n}$ & $\mathbf{X} \pm \mathbf{S D}$ & $\mathbf{p}$ \\
\hline Có bệnh mạch máu & 81 & $4,95 \pm 1,52$ & \multirow{2}{*}{$<0,05$} \\
\hline Không có bệnh mạch máu & 10 & $3,60 \pm 1,43$ & \\
\hline Chung & $\mathbf{9 1}$ & $\mathbf{4 , 8 0} \pm \mathbf{1 , 5 6}$ & \\
\hline
\end{tabular}

Nhận xét: Nhóm bệnh mạch máu có $\mathrm{CHA}_{2} \mathrm{DS}_{2}$-VASc trung bình cao hơn nhóm không có bệnh mạch máu là 4,95 $\pm 1,52$ điểm so với 3,60 $\pm 1,43$ điểm, $(\mathrm{p}<0,05)$.

\section{BÀN LUẦN}

Qua nghiên cứu, điều tra 91 đối tượng về YTNC trên bệnh nhân đột quỵ có rung nhĩ không bệnh van tim, chúng tôi có nhận xét và bàn luận như sau:

\section{1. Đặc điểm chung của bệnh nhân đột quy. \\ 4.1.1. Phân bố theo tuổi}

Những nghiên cứu khảo sát trên nhóm đối tượng trẻ tuổi cho kết quả khác biệt: Tại Phần Lan, Putuala J. (2009) tuổi thường gặp là 15 đến 49 tuổi, trong đó tần suất đột quỵ tăng mạnh ở tuổi 40 (mẫu nghiên cứu là 1.008 đối tượng đột quỵ) tuổi TB là 41,3 \pm 7,6 tuổi [27], kết quả này khá phù hợp với nghiên cứu của Morikawa Y. tại Nhật Bản [24]. Tuy nhiên, nghiên cứu Van Alebeek (2017) lại cho thấy, tuổi đột quỵ ở người trẻ thường dao động trong khoảng từ 18 đến 50 tuổi, tuổi $\mathrm{TB}$ ghi nhận là 40,7 \pm 7,7 tuổi [30].

Trước đây đột quỵ não thường xảy ra ở những người cao tuổi, nhưng ngày nay có khoảng $25 \%$ ca đột quỵ lại xảy ra ở những người trẻ tuổi. Đột quỵ ở người trẻ đang có chiều hướng gia tăng đáng báo động và thường gặp ở những người lạm dụng bia, rượu, thuốc lá, sử dụng các chất kích thích [17]

\subsubsection{Phân bố theo giới}

Theo y văn ghi nhận nam giới có nguy cơ đột quy cao hơn nữ giới, nghiên cứu trong nước của Lê Thị Hòa Bình (2010) nam chiếm $69,1 \%$ nhiều hơn gấp 2,23 lần so với nữ (30,9\%) [1], Nguyễn Tiến Đoàn (2018) tỷ lệ này là $1,4(178 / 130)$ [4]. Một số nghiên cứu 
nước ngoài là Caso V. (2010) nghiên cứu trên 1.136 bệnh nhân đột quỵ tỷ lệ nam/nữ là 1,3 (642/494) [15], Chao T. F (2014) ghi nhận tỷ lệ nam là $54 \%$ so với $46 \%$ [16]; Điều này có thể được lý giải do bệnh nhân nam có nhiều yếu tố nguy cơ với các bệnh lý hơn do thói quen uống rượu, hút thuốc... là những yếu tố được ghi nhận có tác động trực tiếp đến sự gia tăng của bệnh lý mạch máu (cả mạch máu nhỏ và mạch máu lớn), đồng thời cũng là yếu tố nguy cơ gây ra tình trạng nhồi máu não.

\subsection{Triệu chứng lâm sàng của bệnh nhân nghiên cứu}

\subsubsection{Tiền sử tăng huyết áp}

Các nghiên cứu đều cho rằng, tăng huyết áp là một yếu tố nguy cơ quan trọng hàng đẩu của đột quỵ và của các bệnh tim mạch nói chung. Nghiên cứu Framingham với thời gian theo dõi trên 38 năm cho thấy tỷ lệ bệnh nhân đột quỵ có tăng huyết áp là $80,8 \%$. Trong khảo sát cộng đồng, tăng huyết áp có tỷ lệ tăng tịnh tiến: $20 \%, 30 \%, 40 \%, 50 \%$ và $60 \%$ theo thứ tự ở các lứa tuổi tương ứng là: $50,60,70,80$ và 90 tuổi [31].

Các nghiên cứu ở trong nước đều nhận thấy, tăng huyết áp là yếu tố nguy cơ hàng đầu của đột quỵ kể cả nhồi máu não và xuất huyết não. Tỷ lệ tăng huyết áp của chúng tôi là $74,7 \%$, tương đồng với một số nghiên cứu trong và ngoài nước ví dụ nghiên cứu Đỗ Minh Chi, (2015) là 75,6\%, [3]

\subsubsection{Suy tim}

Rung nhĩ và suy tim thường hay mắc phải trên cùng bệnh nhân. Không những do cùng nguyên nhân mà còn phối hợp và tác động qua lại với nhau. Suy tim và đột quỵ thường cùng tồn tại và có cùng yếu tố nguy cơ phổ biến là rung nhĩ. Mặc dù nguy cơ đột quỵ ở bệnh nhân suy tim cao gấp 2-3 lần so với người không bị suy tim nhưng suy tim có phải là nguy cơ cao hay không vẫn còn chưa rõ ràng [5], Theo Adelborg K (2017) nghiên cứu đoàn hệ dựa trên dân số báo cáo rẳng bệnh nhân mắc suy tim có nguy cơ cao mắc tất cả các loại của đột quỵ so với dân số chung [12].

Theo Pana TA (2019) suy tim và rung nhĩ đều có liên quan đến việc tăng nguy cơ tái phát đột quỵ. Nghiên cứu của tác giả này cho thấy bệnh nhân mắc cả rung nhĩ và suy tim làm tăng nguy cơ tử vong khi nhập viện đột quỵ cấp[26]

\subsection{3. Đái tháo đường}

Tại các nước Âu Mỹ tỷ lệ đái tháo đường ở người lớn hơn 70 tuổi là $16 \%$ (nam) và $20 \%$ (nữ). Người bị đái tháo đường nguy cơ bị đột quỵ gấp 2 lần so với người không bị bệnh này. Đái tháo đường thường gây ra các bệnh lý xơ vữa ở mạch vành, mạch não, động mạch đùi. Các nghiên cứu ở bệnh nhân đột quỵ và những nghiên cứu tiến cứu đã khẳng định đái tháo đường làm tăng tần suất đột quỵ [13].

Đái tháo đường và tăng huyết áp là hai bệnh phổ biến đồng thời là yếu tố nguy cơ độc lập hàng đầu của bệnh tim mạch, bệnh thận và vữa xơ động mạch. Sinh bệnh học của bệnh tăng huyết áp ở bệnh nhân đái tháo đường típ 1 và 2 là khác nhau. Trong mọi trường hợp, tăng huyết áp làm nặng tiến triển của bệnh nhân đột quỵ não và làm tăng nguy cơ của cả hai biến chứng mạch máu lớn và mạch máu nhỏ [13].

\subsubsection{Tiền sử có TIA hoặc đột quy.}

Trong nghiên cứu chúng tôi có $27,5 \%$ tiền sử đột quỵ. Kết quả này tương đương với nghiên cứu của Jorfida M (2016), cho thấy tiền sử đột quỵ $(27,6 \%)$ [20].

Có thể nhận thấy, các bệnh nhân có tiền sử TIA và đột quỵ không chỉ là yếu tố nguy cơ làm bệnh dễ tái phát và nặng lên mà còn để lại những di chứng nặng nề cả về thể chất và tâm thần nhất là những người cao tuổi. Vì vậy, tất cả các người bệnh đột quỵ đều cần phải được điều trị dự phòng tái phát bằng cách giải quyết các yếu tố nguy cơ, đặc biệt là tăng huyết áp, phục hồi chức năng và hòa nhập cộng đồng để hạn chế tới mức thấp nhất hậu quả do đột quỵ gây nên.

\subsubsection{Các bệnh mạch máu}

Các bệnh lý về mạch máu có những dấu hiệu rất dễ் nhận biết nhưng hay bị bỏ qua. Khi bệnh không được điều trị kịp thời thường biến chứng rất nguy hiểm. Những bệnh mạch máu thường gặp là: bệnh mạch vành và bệnh lý mạch máu não.

Kết quả chúng tôi ghi nhận có tỷ lệ bệnh mạch máu cao nhất là $89 \%$, so với các tác giả Nguyễn Thị Bảo Liên (2018), bệnh mạch máu 
$(12,3 \%)$ [9]. Khan N.A và cs (2017) nghiên cứu 3 vùng về bệnh tim mạch ở bệnh nhân đột quy ghi nhận tại Trung quốc là $13,7 \%$; người da trắng $(10,3 \%)$ và $\mathrm{Nam} A ́ \mathrm{~A}(11,0 \%)$ [22]

Theo Go As (2014), Hiệp hội tim mạch học Hoa Kỳ (AHA) cho rằng bệnh lý mạch máu là nguyên nhân hàng đầu của tử vong toàn cầu, làm tăng nguy cơ biến cố mạch máu ở bệnh nhân có tiền sử đột quỵ- cơn thiếu máu não thoáng qua, đặc biệt nguy cơ dài hạn về biến cố động mạch vành [28].

\subsubsection{Rối loạn chuyển hóa lipid}

Rối loạn chuyển hóa lipid là một trong những yếu tố khởi đầu cho quá trình hình thành và phát triển của xơ vữa động mạch. Thực ra các tổn thương xơ vữa động mạch xuất hiện rất sớm nhưng chỉ biểu hiện trên lâm sàng ở lứa tuổi 50-60 tuổi (biểu hiện trên xét nghiệm là các rối loạn chuyển hóa lipid máu).

Kết quả này tương đương với Đỗ Văn Việt, (2016) 66,91\% [11] và cao hơn với một số nghiên cứu, Đố Minh Chi, Cao Phi Phong (2015) $22,1 \%$ [3].

\subsubsection{Tiền sử bệnh phối hợp của đối tựng nghiên cúu}

Trong nghiên cứu của chúng tôi, đa số các bệnh nhân có từ 2 yếu tố nguy cơ trở lên (chiếm tới $85,7 \%$ ) trong đó nhóm bệnh có hai yếu tố nguy cơ chiếm tỷ lệ cao nhất $(40,6 \%)$; chỉ có $13,2 \%$ nhóm bệnh nhân có 1 yếu tố nguy cơ, và $1,1 \%$ không có tiền sử bệnh (biểu đồ 3.4) đặc biệt có tới 17 bệnh nhân có tới 4 yếu tố nguy cơ chiếm $18,7 \%$. Hai yếu tố nguy cơ hay gặp là tăng huyết áp và bệnh mạch máu. So sánh nghiên cứu của Đoàn Thị Bích (2011) trên 125 bệnh nhân cho thấy có 1 yếu tố nguy cơ chiếm cao nhất $45,6 \%, 2$ yếu tố nguy cơ là $22,4 \%$ và $\geq$ 4 yếu tố nguy cơ chỉ chiếm 7,2\% [2].

Việc có nhiều yếu tố nguy cơ trên một người bệnh làm cho tăng tỷ lệ cũng như diễn biến đột quỵ phức tạp và nặng nề hơn. Do đó việc tầm soát, sàng lọc các yếu tố nguy cơ cần được làm thường xuyên ở những người cao tuổi để có chiến lược dự phòng tiên phát cũng như điều trị dự phòng thứ phát, giúp giảm tỷ lệ mắc đột quỵ và tăng chất lượng điều trị ngay khi người bệnh mới xuất hiện yếu tố nguy cơ, đặc biệt những YTNC có thể điều chỉnh được.

\subsection{Yếu tố nguy cơ theo thang điểm $\mathrm{CHA}_{2} \mathrm{DS}_{2}$-VASC \\ 4.3.1. Tỷ lệ điểm $C H A_{2} D S_{2}-V A S c$ của bệnh nhân}

Kết quả chúng tôi ghi nhận điểm $\mathrm{CHA}_{2} \mathrm{DS}_{2}$-VASc là 5 chiếm tỷ lệ cao nhất $27,5 \%$, tiếp theo là $\mathrm{CHA}_{2} \mathrm{DS}_{2}$-VAS 4 điểm chiếm $23,1 \%, \mathrm{CHA}_{2} \mathrm{DS}_{2}$-VASc điểm 6 và 7 lần lượt là $14,3 \%$ và $13,2 \%, \mathrm{CHA}_{2} \mathrm{DS}_{2}$-VASc điểm 8 thấp nhất với chỉ $3,3 \%$. Điểm TB của $\mathrm{CHA}_{2} \mathrm{DS}_{2}$-VASc là $4,80 \pm 1,56$; điểm nhỏ nhất là 2 và lớn nhất là 8 . Nhóm $\leq 2$ điểm chiếm $9,9 \%$ và nhóm $>2$ điểm là $90,1 \%$ (bảng 3.7 )

Nghiên cứu của Bùi Thúc Quang (2013) cho thấy phân bố khá đều ở các nhóm: 1 điểm chiếm $24,8 \% ; 2$ điểm là $17,9 \% ; 3$ điểm là $19,7 \%$ và ít hơn ở nhóm 6 điểm 5,1\%, 7 điểm (4,3\%), không có $\mathrm{CHA}_{2} \mathrm{DS}_{2}$-VASc 8 điểm [10]

4.3.2. Phân tầng nguy co đột quy. theo thang điểm $\mathrm{CH} A_{2} D S_{2}-V A S C$

So sánh với một số tác giả trong và ngoài nước: Đỗ Minh Chi, Cao Phi Phong (2015) cho thấy tỷ lệ $\mathrm{CHA}_{2} \mathrm{DS}_{2}$-VASC $\geq 2$ điểm chiếm 75,5\% [3] Lại Tố Hương (2013) ghi nhận nguy cơ đột quỵ cao (điểm $\mathrm{CHADS}_{2} \geq 2$ ) chiếm đa số mẫu nghiên cứu (80,4\%), nguy cơ đột quỵ trung bình (điểm $\mathrm{CHADS}_{2}=1$ ) và nguy cơ đột quỵ thấp (điểm $\mathrm{CHADS}_{2}=0$ ) chiếm tỷ lệ lần lượt là $13,7 \%$ và $5,9 \%$ [8].

Kết quả chúng tôi có nguy cơ đột quỵ cao tương đương với nghiên cứu của Jaakkola $\mathrm{J}$ (2016), điểm $\mathrm{CHA}_{2} \mathrm{DS}_{2}$-VASC trung bình là $4,0 \pm 2,0$; Nhóm $0-1$ điểm chiếm $9,9 \%$; và nhóm $\geq 2$ điểm là $90,1 \%$ [19] .

Điểm $\mathrm{CHA}_{2} \mathrm{DS}_{2}$-VASC trung bình của chúng tôi cao hơn các tác giả Okummra $\mathrm{Y}$, (2020) khảo sát trên 12.289 bệnh nhân đột quỵ có rung nhĩ không do bệnh van tim theo thang điểm $\mathrm{CHA}_{2} \mathrm{DS}_{2}$-VASC ghi nhận điểm $\mathrm{TB}$ là $2,9 \pm 1,7$; nhóm nguy cơ đột quỵ thấp $\left(\mathrm{CHA}_{2} \mathrm{DS}_{2}\right.$-VASC $\left.0-1\right)$ chiếm $22 \%$ và nhóm nguy cơ đột quỵ cao $\left(\mathrm{CHA}_{2} \mathrm{DS}_{2}\right.$-VASC $\geq 2$ điểm) là $78 \%$ [25].

\subsubsection{Múc độ nguy co đột quy theo thang điểm $\mathrm{CHA}_{2} D S_{2}-V A S C$}

Để phân tầng nguy cơ đột quị ở bệnh nhân rung nhĩ, đặc biệt là $\mathrm{RN}$ không do bệnh van tim, nhiều thang điểm lâm sàng đã được sử 
dụng như $\mathrm{CHADS}_{2}, \mathrm{CHA}_{2} \mathrm{DS}_{2}$-VASc. Hiện nay, thang điểm $\mathrm{CHA}_{2} \mathrm{DS}_{2}-\mathrm{VASc}$ được Hội Tim mạch Châu Âu [14] Hội Tim mạch Hoa Kỳ [23] khuyến cáo sử dụng nhiều nhất. U’u điểm của thang điểm này là đơn giản, dễ nhớ và thông tin chủ yếu dựa vào khai thác tiền sử và khám lâm sàng.

Kết quả của chúng tôi CHA2DS2-VASc không có điểm 0 và 1 , nên mức độ đột quỵ chỉ có trung bình và cao. Có 17 trường hợp nguy cơ trung bình chiếm $18,7 \%$ và nguy cơ cao là $81,3 \%$; không có nguy cơ thấp (bảng 3.8)

\subsubsection{Yếu tố nguy co theo thang điểm $\mathrm{CHA}_{2} \mathrm{DS}_{2}-\mathrm{VASC}$}

Xét các yếu tố nguy cơ theo $\mathrm{CHA}_{2} \mathrm{DS}_{2}$ VASc với 8 biến số cho thấy tỷ lệ có bệnh mạch máu chiếm cao nhất với $89,0 \%$; tiếp đến là tăng huyết áp $74,7 \%$, tuổi $\geq 75(61,5 \%)$ và giới nữ (53,8\%) (bảng 3.10)

Kết quả chúng tôi phù hợp với nghiên cứu của Nguyễn Thị Bảo Liên (2018) với điểm $\mathrm{CHA}_{2} \mathrm{DS}_{2}$-VASc ở nữ cao hơn nam lần lượt là $3,59 \pm 1,65$ điểm so với 2,04 $\pm 1,37$ điểm [9]. Tương tự, nghiên cứu của Fang MC (2018) khảo sát sự khác biệt nguy cơ giữa 2 giới ghi nhận tỷ lệ nữ có điểm $\mathrm{CHADS}_{2}$ trung bình $\geq 2$ cao hơn nam, lần lượt là $53,6 \%$ và 43,6\% [18]

Ekker MS và cs (2019) ghi nhận tỷ lệ đột quỵ lần đầu tiên ở thanh niên tăng theo cấp số nhân với tuổi ở cả hai giới (hệ số tương quan $\mathrm{R}^{2}=0,98$ ở nam và $\mathrm{R}^{2}=0,99$ ở nữ; $\mathrm{R}^{2}$ là thước đo mức độ tương quan của dữ liệu với phương trình hồi quy, trong trường hợp này chỉ ra sự gia tăng theo cấp số nhân). Ở tất cả các nhóm tuổi, tỷ lệ mắc bệnh ở nữ cao hơn nam, ngoại trừ những người từ 44-49 tuổi. IRR của phụ nữ so với nam giới giảm theo tuổi từ 1,93 $(95 \%$ CI 1,62-2,31) ở 18-24 tuổi xuống 1,06 (95\% CI 1,01-1,11) ở 45-49 tuổi [17].

\section{KẾT LUẬN}

Qua nghiên cứu điều tra 91 đối tượng về yếu tố nguy cơ trên bệnh nhân đột quỵ có rung nhĩ không do bệnh lý van tim, chúng tôi có kết luận như sau:

- Điểm $\mathrm{CHA}_{2} \mathrm{DS}_{2}$-VASC trung bình là 4,80 $\pm 1,56$ điểm, nhóm $\leq 2$ điểm chiếm $9,9 \%$ và nhóm $>2$ điểm là $90,1 \%$.

- Nguy cơ đột quỵ não có $\mathrm{CHA}_{2} \mathrm{DS}_{2}-\mathrm{VASc}$ = 4-5 chiếm 50,5\%; nguy cơ cao $\mathrm{CHA}_{2} \mathrm{DS}_{2-}$ VASc $\geq 6$ là $30,8 \%$ và nguy cơ thấp là $18,7 \%$.

- Các yếu tố nguy cơ là bệnh mạch máu chiếm $89,0 \%$; tăng huyết áp là $74,7 \%$; suy tim $45,1 \%$, tiền sử đột quỵ $27,5 \%$ và đái tháo đường $12,1 \%$, tuổi $\geq 75$ là $61,5 \%$; tuổi $65-74$ chiếm $27,5 \%$.

- Nữ có điểm $\mathrm{CHA}_{2} \mathrm{DS}_{2}$-VASc trung bình cao hơn nam $(p<0,01)$

- Nhóm $\geq 75$ tuổi có điểm $\mathrm{CHA}_{2} \mathrm{DS}_{2}$-VASc trung bình cao hơn nhóm $<75$ tuổi $(p<0,01)$

- Nhóm THA, Suy tim, bệnh mạch máu có điểm $\mathrm{CHA}_{2} \mathrm{DS}_{2}$-VASc trung bình cao hơn nhóm không THA $(p<0,05)$

- Nhóm đái tháo đường có điểm $\mathrm{CHA}_{2} \mathrm{DS}_{2}-$ VASc trung bình cao hơn nhóm không đái tháo đường $(\mathrm{p}>0,05)$

- Nhóm tiền sử đột quỵ có điểm $\mathrm{CHA}_{2} \mathrm{DS}_{2}-$ VASc trung bình cao hơn nhóm không có tiền sử đột quỵ $(\mathrm{p}<0,01)$

\section{TÀI LIỆU THAM KHẢO}

1. Lê Thị Hoà Bình (2010), Đặc điểm lâm sàng và cận lâm sàng của thiếu máu não cuc bộ ờ người cao tuổi tại bệnh viện Thống Nhất, Luận án tiến sĩ Y học, ĐH Y Dược TP Hồ Chí Minh

2. Đoàn Thị Bích (2011), Nghiên cưu đặc điểm lâm sàng, yếu tố nguy co và nguyên nhân của nhồi máu não ở người trường thành dưới 50 tuổi, Luận văn Thạc sĩ, ĐHY Hà Nội

3. Đỗ Minh Chi, Cao Phi Phong (2015), Nghiên cứu các yếu tố tiên lượng trên bệnh nhân nhồi máu não có rung nhĩ, $Y$ học TP Hồ Chí Minh, 19(1), tr.240-245

4. Nguyễn Tiến Đoàn (2018), Nghiên cứu một số yếu tố nguy co và tiên luợng ở ngườ bệnh cao tuổi bị đột quy thiếu máu não cuc bộ tại Bệnh viện Đa khoa tỉnh Phú Tho, Luận án tiến sĩ, Viện nghiên cứu Khoa học Y Dược lâm sàng 108.

5. Hội tim mạch học Việt nam (2015). Khuyến cáo về chẩn đoán và điều trị suy tim 
6. Hội tim mạch học Việt nam (2016). Khuyến cáo về chẩn đoán và điều trị rung nhĩ

7. Hội tim mạch học Việt nam (2008). Khuyến cáo về chẩn đoán và điều trị trị nhồi máu não cấp (Đột quỵ thiếu máu não)

8. Lai Tố Hương, Hà Kim Chi (2013), Khảo sát sử dụng thuốc chống huyết khối dự phòng đột quỵ theo thang điểm CHADS2 trên bệnh nhân rung nhĩ, $Y$ học TP Hồ Chí Minh 17(3), tr.90-95.

9. Nguyễn Thị Bảo Liên (2018), Đặc điểm lâm sàng, cận lâm sàng, các yếu tố nguy co đột quy của nhồi máu não cấp ở bệnh nhân rung nhĩ không do bệnh van tim, Luận án tiến sĩ ĐHY Hà Nội

10. Bùi Thúc Quang, Vũ Điện Biên, Phạm Nguyên Sơn (2013). Giá trị dự báo huyết khối tiểu nhĩ trái bằng thang điểm $\mathrm{ChaDS}_{2}$; $\mathrm{Cha}_{2} \mathrm{DS}_{2} \mathrm{VASc}$, các thông số siêu âm tim thành ngực ở bệnh nhân rung nhĩ không có bệnh van tim, Tap chi $Y$ duợc hoc, Trường Đại học Y dược Huế, 11, tr 36-43.

11. Đỗ Văn Việt, Nguyễn Văn Tuấn (2016), Đặc điểm đột quỵ nhồi máu não tại bệnh viện quân y 103, Tạp chí Y-Dược học quân sue, p.56-62

12. Adelborg K., Szépligeti S., Sundbøll J., Horváth-Puhó E., et al. (2017). Risk of Stroke in Patients With Heart Failure. Stroke, 48(5), p.1161-1168.

13. American Diabetes Association (2017), Standards of Medical Care in Diabetes 2017, pp 1 - 33.

14. Camm A. John; Kirchhof P, Gregory Y.H. Lip (2011), Guidelines for the management of atrial fibrillation, European Heart Journal.

15. Caso V, Paciaroni M, Agnelli $G$ et al (2010), Gender differences in patients with acute ischemic stroke, Womens Health (Lond), 6(1), 5157.

16. Chao T.-F., Liu C.-J., Chen S.-J., Wang K.-L., al. (2014). Hyperuricemia and the risk of ischemic stroke in patients with atrial fibrillation - Could it refine clinical risk stratification in AF? International Journal of Cardiology (170), 344-349
17. Ekker M. S., Verhoeven J. I., Vaartjes, I., van Nieuwenhuizen, K. M., et al. (2019). Stroke incidence in young adults according to age, subtype, sex, and time trends. Neurology, 10.1212

18. Fang MC, et al. (2005). Gender differences in the risk of ischemic stroke and peripheral embolism in atrial fibrillation: the AnTicoagulation and Risk factors In Atrial fibrillation (ATRIA) study. Circulation, 112(12), pp. 1687-1691.

19. Jaakkola J., Mustonen P., Kiviniemi T., Hartikainen J. E. K., et al. (2016). Stroke as the First Manifestation of Atrial Fibrillation, PLOS ONE, 11(12), e0168010.

20. Jorfida M., Antolini M., Cerrato E., Caprioli M. G., et al. (2016). Cryptogenic ischemic stroke and prevalence of asymptomatic atrial fibrillation. Journal of Cardiovascular Medicine, 17(12), 8

21. Hong, H. J., Kim, Y. D., Cha, M.-J., Kim, J., et al (2011). Early neurological outcomes according to CHADS2score in stroke patients with non-valvular atrial fibrillation. European Journal of Neurology, 19(2), 284-290.

22. Khan N. A., McAlister F. A., Pilote L., Palepu A., et al (2017). Temporal trends in stroke incidence in South Asian, Chinese and white patients: A population based analysis. PLOS ONE, 12(5), e0175556.

23. Kirchhof P., Benussi S., Kotecha D., Ahlsson A., (2016). 2016 ESC Guidelines for the management of atrial fibrillation developed in collaboration with EACTS. European Heart Journal, 37(38), 289

24. Morikawa Y., Nakagawa H., Naruse Y., Nishijo M., et al. (2000). Trends in Stroke Incidence and Acute Case Fatality in a Japanese Rural Area: The Oyabe Study. Stroke, 31(7), 1583-1587.

25. Okumura K., Tomita H., Nakai M., et al (2020). Risk factors associated with ischemic stroke in japanese patients with nonvalvular atrial fibrillation, JAMA Network Open, 3(4), e202881 
26. Pana T. A., McLernon D. J., Mamas M. A., et al. (2019). Individual and combined impact of heart failure and atrial fibrillation on ischemic stroke outcomes. Stroke,50, p.1838-1845

27. Putaala J., Metso, A. J., Metso T. M., Konkola N., Kraemer Y., et al (2009). Analysis of 1008 consecutive patients aged 15 to 49 with first-ever ischemic stroke: the helsinki young stroke registry. Stroke, 40(4), 1195-1203.

28. Rothwell P. M. (2000). Carotid Artery Disease and the Risk of Ischaemic Stroke and Coronary Vascular Events, Cerebrovascular Diseases, 10(5),21-33

29. Torp-Pedersen C., Hansen, M., Lip, G., \& Olesen J. (2012). The value of the
CHA2DS2-VASc score for refining stroke risk stratification in patients with atrial fibrillation with a CHADS2 score 0-1: A nationwide cohort study. Thrombosis and Haemostasis, 107(06), 1172-1179

30. Van Alebeek, M. E., Arntz, R. M., Ekker, M. S., Synhaeve, N. E., et al. (2017). Risk factors and mechanisms of stroke in young adults: The FUTURE study. Journal of Cerebral Blood Flow \& Metabolism, 38(9), p.1631-1641

31. Wang TJ, Larson MG, Levy D, et al (2003), . Temporal relations of atrial fibrillation and congestive heart failure and their joint influence on mortality the Framingham Heart Study.Circulation, $107,2920-2925$ 